\title{
New evidence for atmospheric mercury transformations in the marine boundary layer from stable mercury isotopes
}

\author{
Ben Yu ${ }^{1,2}$, Lin Yang ${ }^{1,3}$, Linlin Wang ${ }^{1,4}$, Hongwei Liu ${ }^{1,3}$, Cailing Xiao ${ }^{4}$, Yong Liang ${ }^{4}$, Qian Liu ${ }^{1}$, Yongguang Yin ${ }^{1}$, \\ Ligang Hu ${ }^{1}$, Jianbo Shi ${ }^{1,2,3}$, and Guibin Jiang ${ }^{1,2,3}$ \\ ${ }^{1}$ State Key Laboratory of Environmental Chemistry and Ecotoxicology, Research Center for Eco-Environmental Sciences, \\ Chinese Academy of Sciences, Beijing 100085, China \\ ${ }^{2}$ School of Environment, Hangzhou Institute for Advanced Study, University of Chinese Academy of Sciences, \\ Hangzhou, 310000, China \\ ${ }^{3}$ College of Resources and Environment, University of Chinese Academy of Sciences, Beijing 100049, China \\ ${ }^{4}$ Institute of Environment and Health, Jianghan University, Wuhan 430056, China
}

Correspondence: Jianbo Shi (jbshi@rcees.ac.cn)

Received: 24 April 2020 - Discussion started: 6 May 2020

Revised: 5 July 2020 - Accepted: 11 July 2020 - Published: 19 August 2020

\begin{abstract}
The marine boundary layer (MBL) is the largest transport place and reaction vessel of atmospheric mercury ( $\mathrm{Hg}$ ). The transformations of atmospheric $\mathrm{Hg}$ in the MBL are crucial for the global transport and deposition of $\mathrm{Hg}$. Herein, $\mathrm{Hg}$ isotopic compositions of total gaseous mercury (TGM) and particle-bound $\mathrm{Hg}$ (PBM) collected during three cruises to Chinese seas in summer and winter were measured to reveal the transformation processes of atmospheric $\mathrm{Hg}$ in the MBL. Unlike the observation results at inland sites, isotopic compositions of TGM in the MBL were affected not only by mixing continental emissions but also largely by the oxidation of $\mathrm{Hg}^{0}$ primarily derived by $\mathrm{Br}$ atoms. $\Delta^{199} \mathrm{Hg}$ values of TGM were significantly positively correlated with air temperature in summer, indicating that processes inducing positive mass-independent fractionation of odd isotopes in TGM could be more active at low temperatures, while the relative processes might be weak in winter. In contrast, the positive $\Delta^{199} \mathrm{Hg}$ and high ratios of $\Delta^{199} \mathrm{Hg} / \Delta^{201} \mathrm{Hg}$ in PBM indicated that alternative oxidants other than $\mathrm{Br}$ or $\mathrm{Cl}$ atoms played a major role in the formation of $\mathrm{Hg}$ (II) in PBM, likely following the nuclear volume effect. Our results suggest the importance of local $\mathrm{Hg}$ environmental behaviors caused by an abundance of highly reactive species and provide new evidence for understanding the complicated transformations of atmospheric $\mathrm{Hg}$ in the MBL.
\end{abstract}

\section{Introduction}

The transport and deposition of atmospheric mercury ( $\mathrm{Hg}$ ) are largely attributed to the transformations among three species, including gaseous elemental $\mathrm{Hg}$ (GEM), gaseous oxidized $\mathrm{Hg}$ (GOM), and particle-bound $\mathrm{Hg}$ (PBM), because of the different resident times and migration abilities of them in the atmosphere (Schroeder and Munthe, 1998). Thus, the transformations of atmospheric $\mathrm{Hg}$ are crucial to the global cycling of $\mathrm{Hg}$. The marine boundary layer (MBL) is the largest transport area and reaction vessel for atmospheric $\mathrm{Hg}$ on Earth. It accepts $3400 \mathrm{Mg} \mathrm{yr}^{-1}$ of $\mathrm{Hg}$ from ocean via evasion and deposits $3800 \mathrm{Mg} \mathrm{yr}^{-1}$ of $\mathrm{Hg}$ into the ocean (UN Environment, 2019). Due to the presence of high relative humidity (RH), abundant sunshine, and atmospheric oxidants, transformations between the three species of atmospheric $\mathrm{Hg}$ have been suggested to occur frequently in the MBL (Hedgecock and Pirrone, 2001; Hedgecock and Pirrone, 2004; Laurier et al., 2003; Sprovieri et al., 2010; Wang et al., 2016a; Weiss-Penzias et al., 2003). Sampling in the MBL provides an opportunity to study atmospheric Hg transformations, e.g., the scavenging of GEM or the generation of GOM (Hedgecock and Pirrone, 2001; Hedgecock and Pirrone, 2004; Laurier et al., 2003; Sprovieri et al., 2010; WeissPenzias et al., 2003; De Simone et al., 2013; Holmes et al., 2010; Peleg et al., 2015), occurring outside of the influences of continental emissions. Although oxidizers in the atmo- 
sphere, including ozone, hydroxyl radicals, nitrate radicals, and halogens (Lin and Pehkonen, 1999; De Simone et al., 2013; Holmes et al., 2010; Peleg et al., 2015; Timonen et al., 2013; Ye et al., 2016; Holmes et al., 2009), have been suggested, the contributions from multiple redox processes of atmospheric $\mathrm{Hg}$ in the MBL have not been clarified. The mechanisms of the atmospheric $\mathrm{Hg}$ transformations in the MBL are also poorly understood.

Compared to other marine studies performed globally, elevated GEM concentrations in the MBL have been observed in areas of Chinese seas by both coastal and cruise-based observations (Fu et al., 2010; Wang et al., 2016a, b; Ci et al., 2011a, b, 2014, 2015). Such observations indicated that anthropogenic emissions from Chinese continental areas impact atmospheric $\mathrm{Hg}$ in the MBL. However, the transformations of atmospheric $\mathrm{Hg}$ in the MBL are rarely investigated in these studies.

The stable $\mathrm{Hg}$ isotopic method has been utilized to trace the sources and environmental processes of atmospheric $\mathrm{Hg}$. A ternary system employing mass-dependent fractionation (MDF, reported as $\delta^{202} \mathrm{Hg}$ ), the mass-independent fractionation (MIF) of odd isotopes (odd-MIF, reported as $\Delta^{199} \mathrm{Hg}$ and $\Delta^{201} \mathrm{Hg}$ ), and the mass-independent fractionation of even isotopes (even-MIF, reported as $\Delta^{200} \mathrm{Hg}$ ) could offer diagnostic information on the source contributions and historical environmental processes of atmospheric $\mathrm{Hg}$. In the troposphere, atmospheric $\mathrm{Hg}$ isotopes fractionate during mixing of plumes with various isotopic compositions and also during physical processes including volatilization from and dissolution to droplets (Estrade et al., 2009), diffusion (Koster van Groos et al., 2014), adsorption and desorption on the airborne particle surfaces (Fu et al., 2019a), and chemical processes (Blum et al., 2014). In addition, odd-MIF suggests the occurrence of photochemical processes when source mixing can be excluded (Bergquist and Blum, 2007); even-MIF signatures diagnose the contributions from wet precipitation in the natural environment (Enrico et al., 2016).

Several studies on atmospheric $\mathrm{Hg}$ isotopes were conducted at coastal areas, where as the receptors for mixing air plumes are from both continents and the MBL (Demers et al., 2015; Fu et al., 2018, 2019a; Rolison et al., 2013; Yu et al., 2016). These reported isotopic compositions in atmospheric $\mathrm{Hg}$ have been suggested as mixing results of continental anthropogenic emissions and the clean air from the MBL. However, the isotopic fractionations that occurred during transformations of atmospheric $\mathrm{Hg}$ in the MBL are diluted by the strong impacts of continental emissions. In order to track the transformations of atmospheric $\mathrm{Hg}$ in the MBL using the isotopic tracing method, in situ sampling is indispensable.

The objective of this study was to track atmospheric $\mathrm{Hg}$ transformations in the MBL using stable Hg isotopes. Both total gaseous Hg (TGM, composed of GEM and GOM) and PBM samples were collected during three cruises to Chinese seas in summer and winter. The isotopic signatures in TGM and PBM were compared with the observation results at con- tinental sites to extract the fractionations outside of the influences from anthropogenic emissions and to reveal the potential mechanisms of the transformation processes of atmospheric $\mathrm{Hg}$ in the MBL.

\section{Materials and methods}

\subsection{Sample collection}

The TGM and PBM samples were collected aboard the Dongfanghong II research vessel during three cruises conducted from 7 to 20 July 2016 (denoted as 2016-summer cruise), 29 December 2016 to 15 January 2017 (denoted as 2016-winter cruise), and 27 June to 15 July 2018 (denoted as 2018-summer cruise).

The TGM collection system was constructed following previous publications (Fu et al., 2014; Yu et al., 2016) and using a chloride activated-carbon (ClC) trap (Fu et al., 2014) to capture the TGM in ambient air. A single TGM system was installed on the vessel during the 2016-summer and 2016winter cruises, and two systems were deployed for the 2018summer cruise. Two total suspended particle (TSP) collection systems equipped with quartz fiber filters were installed next to the TGM collection systems for the 2018-summer cruise. Sampling was interrupted during bouts of inclement weather occasionally experienced during the cruises and thus was not continuous (Supplement Table S1). Sampling durations were divided into daytime and nighttime periods during the 2016-summer and 2018-summer cruises, and 24h continuous sampling was conducted during the 2016-winter cruise. See the Supplement for more details.

\subsection{Preconcentration}

A thermal decomposition method using double-stage tube furnaces was applied for the preconcentrations (Sun et al., 2013; Yu et al., 2016). Acid-trapping solution (40\%, $2 \mathrm{HNO}_{3} / 1 \mathrm{HCl}, v / v$ ) (Sun et al., 2013) was utilized to capture the released $\mathrm{Hg}$. The $\mathrm{Hg}$ concentrations in the trapping solutions were then measured by cold vapor atomic fluorescence spectrometry (CVAFS) following US EPA Method 1631. The sample solutions with $\mathrm{Hg}$ concentrations $>2 \mathrm{ng} \mathrm{mL}^{-1}$ were then diluted to $1 \mathrm{ng} \mathrm{mL}^{-1}$ to decrease the acid concentration to $<20 \%(v / v)$. Other sample solutions with lower total mercury $(\mathrm{THg})$ concentrations were grouped based on daytime and nighttime sampling. In each group, the samples were treated with a purge-trap method using $\mathrm{SnCl}_{2}$ solution and the same acid-trapping solution and then diluted to $1 \mathrm{ng} \mathrm{mL}{ }^{-1}$. The grouped samples were marked in the Supplement Table S1. See the Supplement for more details.

\subsection{Isotopic measurements}

Isotopic compositions of the solution samples were measured by a Neptune Plus multicollector inductively coupled plasma 
mass spectrometer using an online vapor generation system (Yin et al., 2010). The instrument was tuned according to a previous publication (Geng et al., 2018) to obtain high sensitivity $\left({ }^{202} \mathrm{Hg}\right.$ : $1.6 \mathrm{~V}$ per $\mathrm{ng} \mathrm{mL}{ }^{-1}$ of $\left.\mathrm{Hg}\right)$ and steady signals (internal precision: $<0.1 \%$ ). $\mathrm{Hg}$ isotopic compositions were calculated according to the following formulas (Blum and Bergquist, 2007):

$$
\begin{gathered}
\delta^{x x x} \mathrm{Hg}_{\text {sample }}=\left(\frac{{ }^{x x x} \mathrm{Hg}_{\text {sample }} /{ }^{198} \mathrm{Hg}_{\text {sample }}}{{ }^{x x x} \mathrm{Hg}_{\mathrm{NIST} 3133} /{ }^{198} \mathrm{Hg}_{\mathrm{NIST} 3133}}-1\right) \\
\times 1000 \\
\Delta^{x x x} \mathrm{Hg}=\delta^{x x x} \mathrm{Hg}-\beta \times \delta^{202} \mathrm{Hg} \\
\beta= \begin{cases}0.252 & (x x x=199) \\
0.502 & (x x x=200) \\
0.752 & (x x x=201)\end{cases}
\end{gathered}
$$

where $x x x$ refers to the mass of each $\mathrm{Hg}$ isotope with amu (atomic mass unit) values of 199, 200, 201, and 202.

The $2 \sigma$ of isotopic compositions for each sample (Table $\mathrm{S} 1$ ) were selected as the greater one of (a) the $2 \sigma$ of replicated measurements of referenced standards including BCR 482 and SRM 3177 or (b) the $2 \sigma$ of replicated measurements of each sample.

\subsection{Quality assurance and quality control (QA/QC)}

Data for QA/QC are listed in Table S2.

The performance of the ClC trap was evaluated twice by parallel sampling and by performing breakthrough experiments. Before sampling, $\sim 0.5 \mathrm{~g}$ of $\mathrm{ClC}$ was loaded into each sorbent trap, and the $\mathrm{THg}$ content in acid solution was $>10 \mathrm{ng}$. Thus, the $\mathrm{ClC}$ blank counted $<6 \%$ ( $<2 \%$ for most high-Hg-content samples without merging in preconcentration step) in all of the acid solution.

BCR 482 (lichen, IRMM, Belgium) was used as the standard to evaluate the recoveries of the preconcentration procedure. The measured isotopic compositions in the two referenced standards, including BCR 482 and SRM 3177 (mercuric chloride standard solution, NIST), were comparable to reported data (Sun et al., 2016; Estrade et al., 2010). Replicate measurements were conducted during $\mathrm{Hg}$ concentration ( $n=3$ ) and isotopic measurement ( $n=2$; except for parallel TGM samples collected in 2018-summer, $n=4)$. Method blanks were excluded when calculating the $\mathrm{Hg}$ concentrations and the preconcentration recoveries. The mass bias during isotopic measurement was calibrated using the samplestandard bracketing method, and using $\mathrm{Tl}$ (thallium) aerosols as an internal spike (Yin et al., 2010).

\subsection{Other supporting data}

The meteorological data collected during the cruises were obtained from an automatic weather station on the Dongfanghong II research vessel.
One of the two parallel sampling filters collected during the 2018-summer cruise was treated to measure $\mathrm{Hg}^{0}, \mathrm{Hg}$ (II), and $\mathrm{Br}$ speciation on airborne particles. The measurements of $\mathrm{Hg}^{0}$ and $\mathrm{Hg}$ (II) in TSPs were conducted by following a previous publication (Feng et al., 2004). One-quarter of a sheet of sampling filter was rolled up and settled in a heating tube installed in a tube furnace. The furnace was maintained at $80^{\circ} \mathrm{C}$ for $2 \mathrm{~h}$ and then maintained at $500^{\circ} \mathrm{C}$ for $2 \mathrm{~h}$. A bubbler filled with $5 \mathrm{~mL}$ acid-trapping solution, the same as used in the preconcentration stage, was connected to the outlet of the heating tube to capture the released $\mathrm{Hg}$ at 80 and $500{ }^{\circ} \mathrm{C}$. Purified nitrogen, used as carrier gas, was maintained at $25 \mathrm{~mL} \mathrm{~min}^{-1}$. The THg in acid-trapping solution was measured using CVAFS following US EPA Method 1631. The other three-quarters of the sampling filter sheet was treated following the National Environmental Protection Standards of the People's Republic of China HJ 799-2016 to obtain the concentration of $\mathrm{Br}$ atom, $\mathrm{Br}$ anion, and organic $\mathrm{Br}$ on TSPs, using ion chromatography.

See the Supplement, Text S3 and Fig. S1, for more details on the calculation and illustration of $72 \mathrm{~h}$ back-trajectories associated with higher and lower $\Delta^{199} \mathrm{Hg}$ in TGM using the HYbrid Single-Particle Lagrangian Integrated Trajectory (HYSPLIT4) model (Rolph et al., 2017; Stein et al., 2015).

\section{Results and discussion}

A summary of measured isotopic values and concentrations is listed in Table 1.

\subsection{Isotopic composition in TGM}

According to a William-York bivariate linear regression (Cantrell, 2008) applying $\delta^{202} \mathrm{Hg}$ and $\Delta^{199} \mathrm{Hg}$ in all of the TGM samples, the observed fitted curve had a slope of $-0.10 \pm 0.01$ (Fig. 1). This fitted curve always indicated a mixing of plumes with different isotopic fingerprints (Demers et al., 2015; Yu et al., 2016; Fu et al., 2018). An $\sim-0.1$ slope could be produced when there is mixing of plumes from anthropogenic emissions characterized by negative $\delta^{202} \mathrm{Hg}$ and near-zero $\Delta^{199} \mathrm{Hg}$ values, with plumes from remote areas characterized by positive $\delta^{202} \mathrm{Hg}$ and negative $\Delta^{199} \mathrm{Hg}$ values. For instance, the three slopes of -0.09 , -0.13 , and -0.07 observed in TGM from Mt. Damei, Mt. Ailao, and Beijing, China, respectively (Yu et al., 2016), or -0.095 observed in TGM/GEM and source materials worldwide (Fu et al., 2018). The eastern region of China is dominated by a subtropical monsoon climate, with winds moving from the mainland to the ocean in winter and reversely in summer (Fig. S1). TGM collected during the 2016-winter cruise, which was supposed to be largely impacted by anthropogenic emissions from mainland China based on the monsoon (Fig. S1), showed positive $\delta^{202} \mathrm{Hg}$ and negative $\Delta^{199} \mathrm{Hg}\left(\delta^{202} \mathrm{Hg}\right.$ : $0.19 \pm 0.30 \%$; $\Delta^{199} \mathrm{Hg}:-0.13 \pm 0.04 \%$, 
Table 1. Statistical summary table of isotopic data in this study. The comparison data from previous publications are characterized for TGM in remote areas (Demers et al., 2013, 2015; Fu et al., 2016, 2018; Yu et al., 2016), GEM in an island located in the East China Sea (Fu et al., 2018), PBM collected at inland sites (Yu et al., 2016; Das et al., 2016; Huang et al., 2015, 2016; Xu et al., 2017), and PBM collected in a coastal site in the USA (Rolison et al., 2013) and the same island in the East China Sea (Fu et al., 2019b).

\begin{tabular}{|c|c|c|c|c|c|c|c|c|c|c|c|}
\hline Sample & Sampling time & $\begin{array}{l}\text { Concentration* } \\
\mathrm{ng}(\mathrm{pg}) \mathrm{m}^{-3}\end{array}$ & ng $(\mathrm{pg}) \mathrm{m}^{-3}$ & $\begin{array}{r}\delta^{202} \mathrm{Hg} \\
(\% o)\end{array}$ & $\begin{array}{r}1 \sigma \\
(\% o)\end{array}$ & $\begin{array}{r}\Delta^{199} \mathrm{Hg} \\
(\%)\end{array}$ & $\begin{array}{r}1 \sigma \\
(\% o)\end{array}$ & $\begin{array}{r}\Delta^{200} \mathrm{Hg} \\
(\%)\end{array}$ & $\begin{array}{r}1 \sigma \\
(\% o)\end{array}$ & $\begin{array}{r}\Delta^{201} \mathrm{Hg} \\
(\% o)\end{array}$ & $\begin{array}{r}1 \sigma \\
(\% o)\end{array}$ \\
\hline TGM & 2016-winter & 1.81 & 0.51 & 0.19 & 0.30 & -0.13 & 0.04 & -0.03 & 0.02 & -0.12 & 0.04 \\
\hline TGM & 2016-summer & 1.31 & 0.31 & -1.48 & 0.56 & 0.01 & 0.05 & -0.03 & 0.04 & -0.02 & 0.04 \\
\hline TGM & 2018-summer & 1.74 & 0.64 & -0.09 & 0.48 & -0.13 & 0.06 & -0.05 & 0.04 & -0.13 & 0.05 \\
\hline PBM & 2018-summer & 14.3 & 19.8 & -0.80 & 0.58 & 0.40 & 0.21 & 0.01 & 0.03 & 0.09 & 0.10 \\
\hline TGM/GEM-remote & & & & 0.54 & 0.38 & -0.21 & 0.04 & -0.05 & 0.03 & -0.20 & 0.04 \\
\hline GEM-island & & & & -0.21 & 0.39 & -0.16 & 0.06 & -0.06 & 0.04 & -0.18 & 0.07 \\
\hline PBM-inland & & & & -1.01 & 0.76 & -0.01 & 0.15 & 0.03 & 0.04 & -0.03 & 0.14 \\
\hline PBM-coastal/island & & & & -0.87 & 0.36 & 0.50 & 0.41 & 0.10 & 0.06 & 0.35 & 0.39 \\
\hline
\end{tabular}

in units of nanogram per cubic meter $\left(\mathrm{ng} \mathrm{m}^{-3}\right)$, and PBM concentrations were reported in units of picogram per cubic meter $\left(\mathrm{pg} \mathrm{m}^{-3}\right)$.

$n=14,1 \sigma)$, echoing the isotopic fingerprints of TGM at the remote sites (Demers et al., 2013, 2015; Fu et al., 2016, 2018; Yu et al., 2016) (Fig. 1). TGM collected during this cruise also showed the highest concentrations $\left(1.81 \pm 0.51 \mathrm{ng} \mathrm{m}^{-3}\right.$, $n=14,1 \sigma)$ among the three cruises, exceeding the background value of the Northern Hemisphere $\left(\sim 1.5 \mathrm{ng} \mathrm{m}^{-3}\right)$ but falling below averaged GEM concentrations measured at both urban and remote sites on the Chinese mainland (urban: $9.20 \pm 0.56 \mathrm{ng} \mathrm{m}^{-3}$; remote: $2.86 \pm 0.95 \mathrm{ng} \mathrm{m}^{-3}$ ) (Fu et al., 2015). Considering that an average wind speed of $6.9 \mathrm{~m} \mathrm{~s}^{-1}$ was measured during this cruise, the air mass leaving the Chinese mainland could reach the vessel within several hours. Therefore, isotopic compositions in TGM collected during the 2016-winter cruise suggested a limited influence from the anthropogenic emissions that diluted in the clean air in the MBL.

On the other hand, TGM collected in the two summer cruises were characterized by significantly negative $\delta^{202} \mathrm{Hg}$ and near-zero $\Delta^{199} \mathrm{Hg}$ values (2016-summer: $\delta^{202} \mathrm{Hg}:-1.48 \pm 0.56 \%$; $\Delta^{199} \mathrm{Hg}: 0.01 \pm 0.05 \%$ o, $n=9,1 \sigma$; 2018-summer: $\delta^{202} \mathrm{Hg}:-0.09 \pm 0.48 \%$; $\Delta^{199} \mathrm{Hg}:-0.13 \pm$ $0.06 \%, n=18,1 \sigma)$ indicating mixing of continental emissions to marine-originated plumes (Fig. 2 process a). TGM collected in the 2016-summer cruise showed near-zero $\Delta^{199} \mathrm{Hg}$ values, most likely inherited from anthropogenic emissions (Demers et al., 2015; Yu et al., 2016; Fu et al., 2018; Sun et al., 2014), but it also showed lower THg concentrations than TGM collected in the other two cruises (Table 1). This result was uncommon, because higher TGM concentrations were always associated with anthropogenic emissions in China (Fu et al., 2015). The positive correlation between TGM concentrations and $\Delta^{199} \mathrm{Hg}$ values in TGM commonly attributed to mixing of anthropogenic emissions and clean air, was also absent $(P>0.05)$ in this cruise (Fig. 3b). Backward trajectory analysis showed that higher $\Delta^{199} \mathrm{Hg}$ values were associated with air masses originated from both mainland China and the open ocean (Fig. S1).

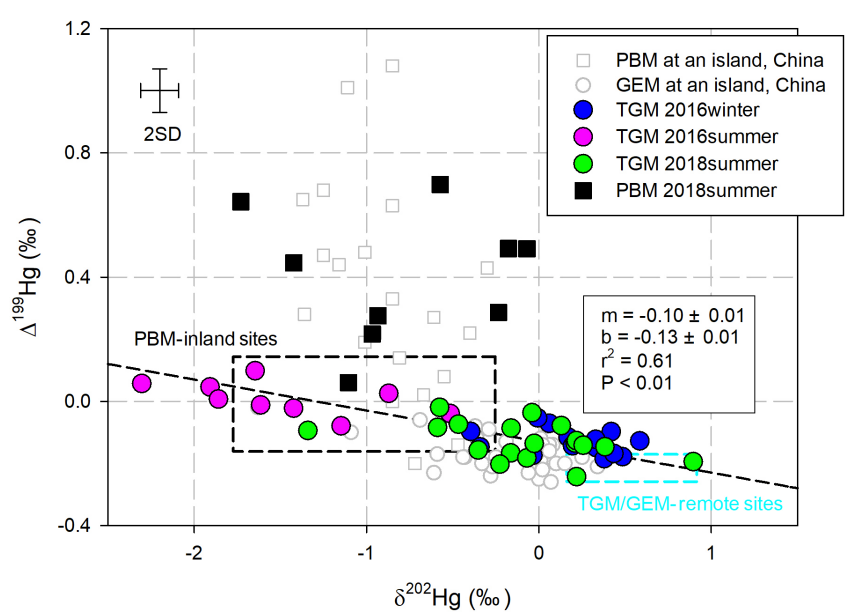

Figure 1. Scatter plot of $\Delta^{202} \mathrm{Hg}$ and $\Delta^{199} \mathrm{Hg}$ in TGM and PBM samples in this study illustrated with reported isotopic compositions in GEM (Fu et al., 2018) and PBM (Fu et al., 2019a) collected at the Huaniao island site in the East China Sea. The reported data ranges (mean $\pm \mathrm{SD}$ ) of isotopic compositions in TGM/GEM are from remote sites globally (Demers et al., 2015; Yu et al., 2016; Demers et al., 2013; Fu et al., 2016), and PBM data are from inland sites (Yu et al., 2016; Das et al., 2016; Huang et al., 2015, 2016; Xu et al., 2017). Error bars refer to max $2 \sigma$ for samples in this study.

These uncommon relationships and the back-trajectory analysis results suggested that alternative reasons, rather than only mixing with continental emissions, should contribute to TGM in the MBL in summer.

\subsection{Isotopic composition in PBM}

The isotopic compositions in PBM collected from the MBL with negative $\delta^{202} \mathrm{Hg}$ and positive $\Delta^{199} \mathrm{Hg}$ values $\left(\delta^{202} \mathrm{Hg}\right.$ : $-0.80 \pm 0.58 \%$; $\left.\Delta^{199} \mathrm{Hg}: 0.40 \pm 0.21 \% o, n=9,1 \sigma\right)$ were distinguishable from those in the TGM (Fig. 1). Similar data have been observed for PBM collected from Huaniao island, China $\left(\delta^{202} \mathrm{Hg}:-0.87 \pm 0.31 \%\right.$; $\Delta^{199} \mathrm{Hg}: 0.34 \pm 0.34 \%$ ) $(\mathrm{Fu}$ 


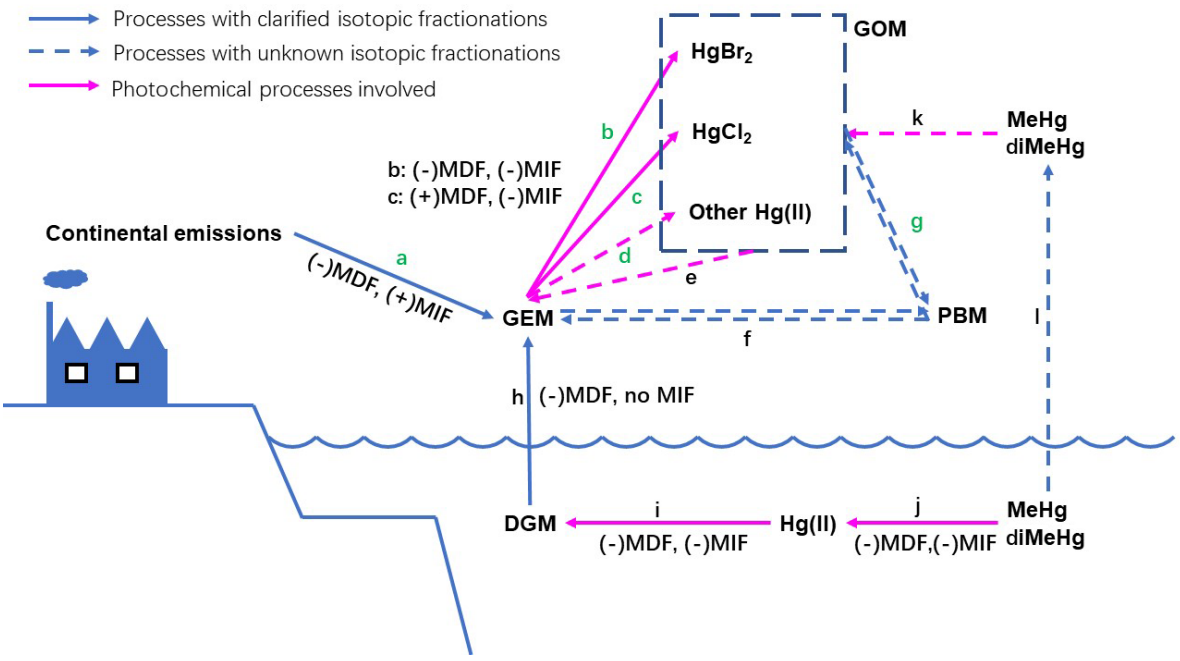

Figure 2. The atmospheric processes of $\mathrm{Hg}$ in the MBL with inducing isotopic fractionations (MDF and only odd-MIF directions). Process a: mixing with continental emissions; $b$ : oxidation by $\mathrm{Br}$ atoms; $\mathrm{c}$ : oxidation by $\mathrm{Cl}$ atoms; $\mathrm{d}$ : oxidations by alternative oxidants; e: photoreductions of gaseous $\mathrm{Hg}(\mathrm{II})$; $\mathrm{f}$ : adsorption and desorption of $\mathrm{Hg}^{0}$ on airborne particle surfaces; $\mathrm{g}$ : adsorption and desorption of $\mathrm{Hg}$ (II) on airborne particle surfaces; h: volatilization of dissolved gaseous $\mathrm{Hg}^{0}$ from surface sea water; i: photoreduction of aquatic $\mathrm{Hg}$ (II); j: photodecomposition of aquatic $\mathrm{MeHg} / \mathrm{diMeHg}$; $\mathrm{k}$ : photodecomposition of gaseous $\mathrm{MeHg} / \mathrm{diMeHg}$; and l: volatilization of dissolved $\mathrm{MeHg} / \mathrm{diMeHg}$.

et al., 2019a). Meanwhile, PBM collected at a coastal site in Grand Bay, USA, showed higher $\Delta^{199} \mathrm{Hg}$ values $\left(\Delta^{199} \mathrm{Hg}\right.$ : $0.83 \pm 0.35 \%$ ) (Rolison et al., 2013). In contrast, other reported isotopic compositions of PBM, almost collected at continental urban and rural sites, have been characterized by negative $\delta^{202} \mathrm{Hg}$ and near-zero $\Delta^{199} \mathrm{Hg}$ due to anthropogenic emissions (Yu et al., 2016; Das et al., 2016; Huang et al., 2015, 2016; Xu et al., 2017).

The isotopic compositions in PBM in this study and the similar isotopic compositions in PBM collected at an island site in China (Fu et al., 2019a) were distinguishable from those collected at inland urban and rural sites, suggesting the dominant influences are from the marine environment rather than continental anthropogenic emissions. The primary species of PBM examined in this study was $\mathrm{Hg}(\mathrm{II})$, accounting for $78.6 \pm 13.0 \%(1 \sigma, n=9$, Table S3) of total PBM. Therefore, the isotopic fractionations between TGM and PBM in the MBL was attributed to $\mathrm{Hg}(\mathrm{II})$ on the particle surfaces.

Slightly negative $\Delta^{200} \mathrm{Hg}$ and positive $\Delta^{200} \mathrm{Hg}$ values were observed in TGM and PBM samples, respectively (Table 1). These near-zero values were comparable to reported data observed in TGM and PBM at most sites globally (Das et al., 2016; Huang et al., 2015; Fu et al., 2018, 2019a, b; Demers et al., 2013, 2015; Enrico et al., 2016). In addition, higher $\Delta^{200} \mathrm{Hg}$ values $(0.19 \pm 0.18 \%, 1 \sigma, n=69)$ have been commonly observed globally in wet precipitation with $\mathrm{Hg}$ (II) as primary species (Chen et al., 2012; Yuan et al., 2018; Gratz et al., 2010; Enrico et al., 2016; Wang et al., 2015). $\Delta^{200} \mathrm{Hg}$ values have been used to evaluate the contribution from wet precipitation (Enrico et al., 2016). Those near-zero $\Delta^{200} \mathrm{Hg}$ values of TGM and PBM in this study indicate limited contributions from $\mathrm{Hg}$ (II) in wet precipitations via photoreduction and re-emission from droplet surfaces to both PBM and TGM. Therefore, gaseous $\mathrm{Hg}^{0}$ oxidation is implied as an important contributor to the high $\Delta^{199} \mathrm{Hg}$ values in PBM.

\subsection{The oxidation processes in the MBL}

MIF induced by the magnetic isotope effect (MIE) mechanism produces a slope of $\sim 1.0$ in the linear regression of $\Delta^{199} \mathrm{Hg}$ and $\Delta^{201} \mathrm{Hg}$ in environmental samples, while a $\sim 1.6$ slope is created as a result of the nuclear volume effect (NVE) (Blum and Bergquist, 2007). Although the linear correlation between $\Delta^{199} \mathrm{Hg}$ and $\Delta^{201} \mathrm{Hg}$ in the PBM was insignificant $(P>0.05)$, ratios of $\Delta^{199} \mathrm{Hg} / \Delta^{201} \mathrm{Hg}(6.8 \pm 8.4$, $1 \mathrm{SD}, n=9)$ in the PBM samples were significantly higher than 1.0 (Fig. 4), which were the common ratios observed in PBM from sites influenced by anthropogenic emissions ( $Y u$ et al., 2016; Das et al., 2016; Huang et al., 2015, 2016; Xu et al., 2017). The observed ratios of $\Delta^{199} \mathrm{Hg} / \Delta^{201} \mathrm{Hg}$ in the PBM were also higher than those collected at an island site in China $\left(\Delta^{199} \mathrm{Hg} / \Delta^{201} \mathrm{Hg}: \sim 1.14\right)(\mathrm{Fu}$ et al., 2019a) and at a coastal site in the USA $\left(\Delta^{199} \mathrm{Hg} / \Delta^{201} \mathrm{Hg}\right.$ : 1.12) (Rolison et al., 2013). The insignificant correlation between $\Delta^{199} \mathrm{Hg}$ and $\Delta^{201} \mathrm{Hg}$ in the PBM and between the isotopic signatures and the percentages of oxidized $\mathrm{Hg}$ in the PBM $(P>0.05$, Table S3) indicate that multiple processes inducing different fractionation rather than a single oxidation process occurred.

To date, few isotopic studies have been performed on isotopic fractionation during GEM oxidation; the mechanism has been suggested to be NVE, according to a study on $\mathrm{Hg}^{0}$ oxidation by $\mathrm{Br}$ and $\mathrm{Cl}$ atoms (Sun et al., 2016). In this study, 
the $\mathrm{Hg}(\mathrm{II})$ in PBM should not be attributed directly to oxidation derived by $\mathrm{Br}$ or $\mathrm{Cl}$ atoms, because $\mathrm{Br}$ and $\mathrm{Cl}$ atoms would induce negative odd-MIF in the produced $\mathrm{Hg}$ (II) during oxidation (Sun et al., 2016) (Fig. 2 processes b and c), which is inconsistent with the positive odd-MIF observed in the PBM with $\mathrm{Hg}$ (II) as the primary form. When the photoreduction of aquatic $\mathrm{Hg}$ (II) involving dissolved organic matter occurs, especially in the MBL with high RH values, the direction of odd-MIF might reverse, because positive odd-MIF would be induced in $\mathrm{Hg}$ (II) in the aquatic layer on particle surfaces (Zheng and Hintelmann, 2009, 2010). The magnitude of photoreduction should be much greater than oxidation derived by $\mathrm{Br} / \mathrm{Cl}$ atoms to produce the observed positive odd-MIF in PBM. However, ratios of $\Delta^{199} \mathrm{Hg} / \Delta^{201} \mathrm{Hg}$ in PBM measured in this study were much higher than 1.0 , a value that has been associated with the photoreduction of aquatic $\mathrm{Hg}(\mathrm{II})$ (Zheng and Hintelmann, 2009, 2010; Bergquist and Blum, 2007). Therefore, $\mathrm{Br} / \mathrm{Cl}$ atom-derived photo-oxidation followed by the photoreduction of aquatic $\mathrm{Hg}$ (II) should not be the primary routine leading to the isotopic compositions in PBM in this study. In addition, the correlation between $\mathrm{Hg}$ isotopic compositions in PBM and speciated $\mathrm{Br}$ concentrations on the TSPs was also absent (Table S3). All of these results suggest that $\mathrm{Br}$ or $\mathrm{Cl}$ atoms were not the direct contributor to $\mathrm{Hg}(\mathrm{II})$ in PBM in the MBL in this study.

Alternative oxidizers other than $\mathrm{Br}$ and $\mathrm{Cl}$ atoms - including the derivatives of $\mathrm{Br} / \mathrm{Cl}$ atoms (e.g., $\mathrm{BrO}, \mathrm{HOCl}, \mathrm{OCl}^{-}$), ozone, hydroxyl radicals, nitrate radicals, and iodine radicals - might play more important roles in $\mathrm{Hg}$ (II) in PBM in this study. The limited isotopic study of $\mathrm{Hg}^{0}$ oxidation prevented specific oxidizers from being identified here. However, the following clues might be helpful to uncover the oxidizers and oxidation processes in the future. According to the isotopic signatures present in TGM and PBM, the primary oxidation of $\mathrm{Hg}^{0}$ by the unidentified oxidizer should induce a positive odd-MIF in the $\mathrm{Hg}$ (II) (Fig. 2 process d). To date, no evidence suggests that odd-MIF could occur during the adsorption of $\mathrm{Hg}$ (II) on the surface of particles (Fig. 2 process g), and the high ratios of $\Delta^{199} \mathrm{Hg} / \Delta^{201} \mathrm{Hg}$ observed in PBM in this study indicate the insignificance of continental impacts. Therefore, the high $\Delta^{199} \mathrm{Hg}$ and high ratios of $\Delta{ }^{199} \mathrm{Hg} / \Delta^{201} \mathrm{Hg}$ in PBM should be primarily attributed to the oxidation of $\mathrm{Hg}^{0}$, following the NVE mechanism. The MIF driven by NVE shares the same direction as the MDF induced during certain processes (Schauble, 2007). Negative MDF must be subsequently induced in $\mathrm{Hg}$ (II) after oxidation, producing the negative $\delta^{202} \mathrm{Hg}$ and positive $\Delta^{199} \mathrm{Hg}$ values in the PBM examined here. Lighter isotopes prefer to be bound to the surfaces of particles, which could be the most probable reason for negative MDF (Fig. 2 processes g).

It should be noted that the primary process leading to the $\mathrm{Hg}(\mathrm{II})$ in PBM could not be the primary oxidation processes of $\mathrm{Hg}^{0}$ in the MBL in this study. GOM attributed to multiple oxidizers would show a variety of occurrence forms, with different adsorption capacities on particle surfaces. The specific forms of $\mathrm{Hg}$ (II) on particle surfaces remains unclear in this study. Meanwhile, the oxidation processes leading to the $\mathrm{Hg}(\mathrm{II})$ in PBM might also occur in the interface reaction layer on particle surfaces. To date, the mechanisms and isotopic fractionations on the formations of GOM are poorly understood, preventing the accurate cognitions of the $\mathrm{Hg}$ (II) in PBM.

On the other hand, all slopes obtained by performing a linear regression of the $\Delta^{199} \mathrm{Hg}$ and $\Delta^{201} \mathrm{Hg}$ in the TGM samples were higher than 1.0 (Fig. 4). A $\sim 1.0$ slope was commonly observed in TGM collected at sites influenced by anthropogenic emissions (Gratz et al., 2010; Yu et al., 2016; Yin et al., 2013). Lower slopes (0.5-0.8) were observed in TGM collected at remote sites located on an island (Fu et al., 2018), at a coast (Demers et al., 2015; Rolison et al., 2013), in a forest (Demers et al., 2013; Fu et al., 2018; Yu et al., 2016), and on a summit (Fu et al., 2016). Among the three cruises, the highest slope was observed in TGM collected in the 2016-summer cruise. Meanwhile, the most near-zero $\Delta^{199} \mathrm{Hg}$ values and lowest TGM concentrations were also observed during this cruise as previously mentioned. This result indicates that alternative factors elevated the slope shape by mixing continental emissions to clean air in the MBL. Positive odd-MIF and high slope of $\Delta^{199} \mathrm{Hg} / \Delta^{201} \mathrm{Hg}(\mathrm{Br}$ : 1.64; $\mathrm{Cl}: 1.89)$ could be induced in the remaining $\mathrm{Hg}^{0}$ pool when oxidation derived by $\mathrm{Br} / \mathrm{Cl}$ atoms occurred (Sun et al., 2016), consistent with the odd-MIF signatures in TGM in this study. Furthermore, negative MDF would occur in the $\mathrm{Hg}^{0}$ pool during the oxidation derived by $\mathrm{Br}$ atoms (Fig. 2 process b), which was also consistent with the negative MDF in TGM collected during two summer cruises, contrasting to the opposite direction of $\mathrm{MDF}$ in $\mathrm{Hg}^{0}$ when oxidation was derived by $\mathrm{Cl}$ atoms (Fig. 2 process c). Therefore, $\mathrm{Br}$ atoms are suggested to be the primary oxidizer for $\mathrm{Hg}^{0}$ in the MBL, echoing the demonstration in previous publications (De Simone et al., 2013; Holmes et al., 2009, 2010; Ye et al., 2016; Obrist et al., 2011).

In addition, potential alternative factors might also contribute to the transformations of TGM in this study, followed by these isotopic clues. A negative correlation $(P<0.01)$ between $\Delta^{199} \mathrm{Hg}$ in the TGM and the atmospheric temperature $\left(17.7\right.$ to $\left.28.4^{\circ} \mathrm{C}\right)$ was observed during the 2018 -summer cruise, indicating that process inducing positive odd-MIF in TGM could be more active at lower temperatures, enhancing the oxidation and scavenging of $\mathrm{Hg}^{0}$ in the MBL (Hedgecock and Pirrone, 2004). However, the correlation was absent during the 2016-summer cruise, which is possibly due to the narrow temperature range involved $\left(22.5\right.$ to $\left.24.7^{\circ} \mathrm{C}\right)$ (Fig. 3a), and also absent during the 2016-winter cruise with lower temperatures. Despite the similar large temperature range $\left(-1.4\right.$ to $\left.12.0^{\circ} \mathrm{C}\right)$ and the similar positive correlation $(P=0.03)$ between $\Delta^{199} \mathrm{Hg}$ in TGM and TGM concentrations with the 2018-summer cruise (Fig. 3b), the absence of 

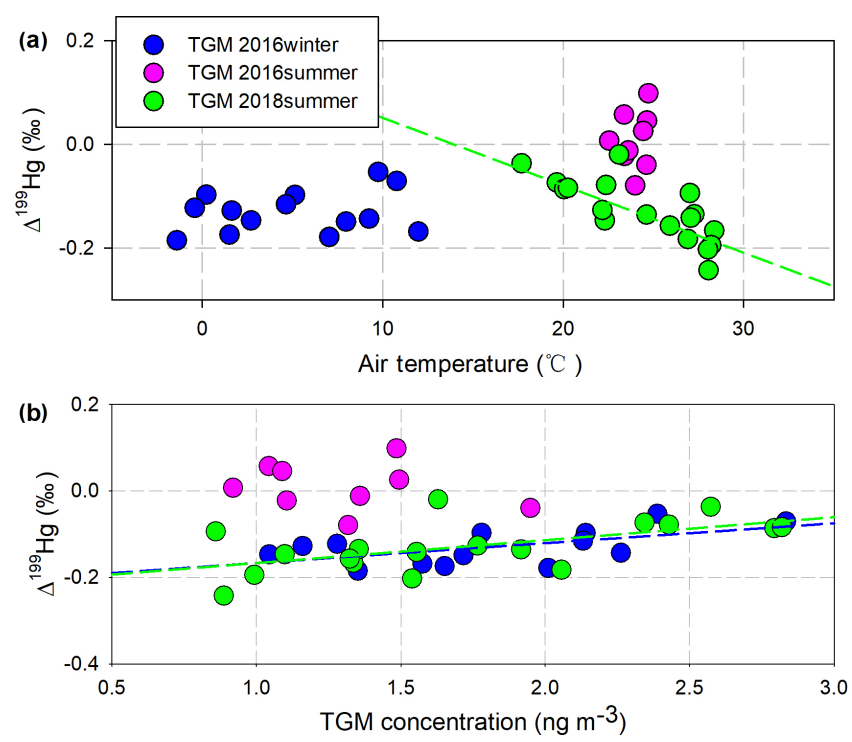

Figure 3. The correlation between $\Delta^{199} \mathrm{Hg}$ in the TGM and air temperatures (a) and between $\Delta^{199} \mathrm{Hg}$ in the TGM and TGM concentrations (b). Regressions lines were colored to match the TGM scatter plots.

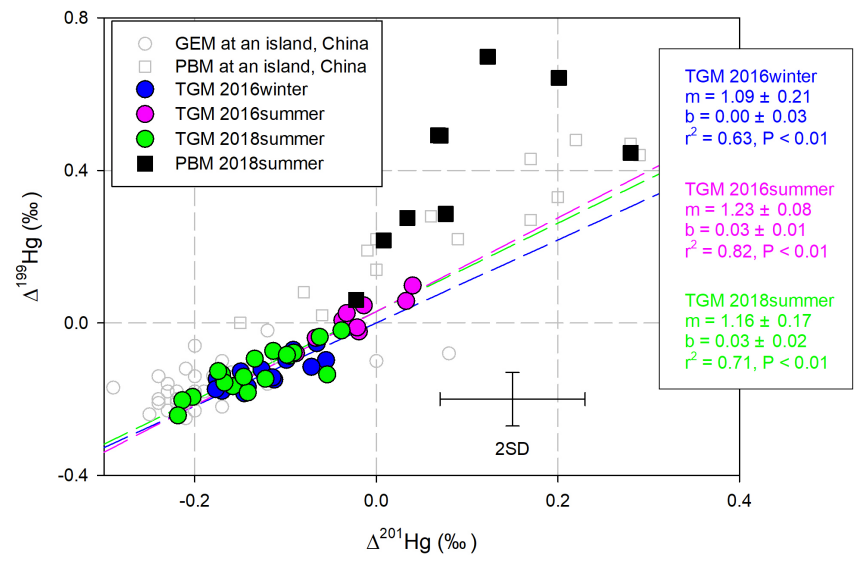

Figure 4. Scatter plot of $\Delta^{199} \mathrm{Hg}$ and $\Delta^{201} \mathrm{Hg}$ in the TGM and PBM samples, illustrated with reported data obtained at Huaniao island sites in the East China Sea (Fu et al., 2018, 2019a). Regression lines were colored to match the TGM scatter plots. Error bars refer to $2 \sigma$ for samples in this study.

a correlation indicated that the process might be weak during the winter cruise.

Emissions from surface sea water (Fig. 2 process $h$ ) are commonly considered to be crucial to influencing atmospheric $\mathrm{Hg}$ in the MBL. Volatilization of dissolved gaseous $\mathrm{Hg}$ should induce negative MDF to $\mathrm{Hg}^{0}$ in the MBL (Zheng et al., 2007), which partially contributed to the negative $\delta^{202} \mathrm{Hg}$ observed in the TGM. This process should not produce odd-MIF (Zheng et al., 2007). According to the negative correlation observed between air temperature and $\Delta^{199} \mathrm{Hg}$ in TGM in the 2018-summer cruise, if the elevated temperature accelerating $\mathrm{Hg}$ volatilization from surface sea water was an important factor shaping isotopic compositions in TGM, the similar correlation between $\Delta^{199} \mathrm{Hg}$ in TGM and air temperature should also be observed in winter, which was absent in this study. Also, isotopic fingerprints of both dissolved gaseous $\mathrm{Hg}^{0}$ and dissolved $\mathrm{Hg}(\mathrm{II})$ in surface sea water in studied areas remained unclarified. Therefore, further studies are necessary to investigate both isotopic fractionation directions and contributions from air-sea surface exchange to isotopic compositions of TGM in the MBL.

Transformations of atmospheric $\mathrm{Hg}$ are complicated. The mechanisms and isotopic fractionations of transformation processes are poorly understood. For instance, the photoreduction of $\mathrm{Hg}(\mathrm{II})$ in the gaseous phase (Lin and Pehkonen, 1999; Horowitz et al., 2017) might also induce odd-MIF in the $\mathrm{Hg}(\mathrm{II})$ remaining on aerosol surfaces (Fig. 2 process e). On the other hand, some gaseous mercury, e.g., methylmercury $(\mathrm{MeHg})$ and dimethylmercury (diMeHg) in plume, have been suggested as important components to atmospheric $\mathrm{Hg}$ in the MBL (Barkay et al., 2011; Baya et al., 2015), and the $\mathrm{Hg}$ isotopic compositions in those components remain unclear (Fig. 2 process k). Effects of these two factors on isotopic compositions in TGM and PBM in the MBL cannot be ruled out.

Odd-MIF occurrences are commonly associated with photochemical reactions (Bergquist and Blum, 2007; Sun et al., 2016). However, isotopic compositions in TGM or PBM collected in daytime and nighttime were insignificantly different in this study ( $T$ test, $P>0.05$ ). A possible reason is that the isotopic fractionations caused by photochemical reactions were diluted due to the low time resolutions during sampling.

\section{Conclusions}

Our measurements of TGM and PBM samples collected in the MBL in China suggest that $\mathrm{Br}$ atoms could be the most probable oxidant to TGM, but alternative oxidants other than $\mathrm{Br}$ or $\mathrm{Cl}$ atoms play a major role in the formation of $\mathrm{Hg}$ (II) in PBM. These oxidation processes could largely shift the $\mathrm{Hg}$ isotopes in the atmosphere, producing negative MDF, positive MIF, and elevated slopes in linear regression results of $\Delta^{199} \mathrm{Hg} / \Delta^{201} \mathrm{Hg}$ in TGM, as well as more positive MIF and high ratios of $\Delta^{199} \mathrm{Hg} / \Delta^{201} \mathrm{Hg}$ in PBM following the NVE mechanism. Lower air temperature could promote relevant processes, causing positive MIF in TGM in summer, while the relative processes might be weak in winter.

To our knowledge, isotopic fractionation that occurs during $\mathrm{Hg}$ environmental processes is diluted by isotopic signatures inherited from multiple emission sources, especially from anthropogenic emissions, and thus has been omitted in previous studies conducted at continental sites when a stable $\mathrm{Hg}$ isotopic tracking method was used. In this study, however, mixing with continental emissions could not entirely 
lead to the isotopic signatures in atmospheric $\mathrm{Hg}$. The observed isotopic signatures indicated the importance of local $\mathrm{Hg}$ environmental behaviors caused by an abundance of highly reactive species. Therefore, isotopic fractionation occurring during environmental processes should be carefully considered when using stable $\mathrm{Hg}$ isotopes to trace sources.

In this study, isotopic compositions in atmospheric $\mathrm{Hg}$ collected from marine areas were different from those collected from most inland areas. Due to the low concentrations of TGM and PBM in the MBL, the time resolutions of isotopic signatures were low. This would dilute potential isotopic fractionations occurring within each sampling period, e.g., the isotopic fractionation following the GOM concentration increasing associated with air temperature and $\mathrm{RH}$ changes, or the potential isotopic diversities associated with the gradient PBM concentration from coastal areas to open seas (Wang et al., 2016a, b). In addition, many atmospheric $\mathrm{Hg}$ transformation processes, e.g., the reduction of $\mathrm{Hg}$ (II) in the gaseous phase, are still poorly understood. Moreover, isotopic fingerprints of many endmembers, e.g., re-emitted gaseous $\mathrm{Hg}$ from surface sea water, are unknown. More studies are therefore needed to constrain isotopic fractionation during these processes and isotopic compositions in these endmembers. When the sampling and isotopic measurement techniques improve, and the isotopic study of the oxidation of gaseous $\mathrm{Hg}$ is performed in the future, stable $\mathrm{Hg}$ isotopes could provide diagnostic information for clarifying the contributions of multiple environmental processes influencing atmospheric $\mathrm{Hg}$ chemistry, and they could serve as effective tools for tracking transformation processes of atmospheric $\mathrm{Hg}$ in the MBL and in other areas with a variety of atmospheric oxidants in the atmosphere.

Data availability. A dataset for this paper can be accessed at https://doi.org/10.5281/zenodo.3748831 (Yu et al., 2020a). Cruise tracks and wind field data for the three sampling cruises can be obtained at https://doi.org/10.5281/zenodo.3871222 (Yu et al., 2020b).

Supplement. The supplement related to this article is available online at: https://doi.org/10.5194/acp-20-9713-2020-supplement.

Author contributions. BY, LY, LW, and HL conducted sampling and measurements. CX and YL assisted the measurements. BY and JS designed research. BY, JS, QL, YY, LH, and GJ wrote the paper.

Competing interests. The authors declare that they have no conflict of interest.

Acknowledgements. The authors would like to thank the captain and crew of Dongfanghong II for their assistance with sample and data collection. The authors gratefully acknowledge the NOAA Air
Resources Laboratory for the provision of the HYSPLIT transport and dispersion model and/or the READY website (https://www. ready.noaa.gov, last access: 25 February 2020) used in this publication.

Financial support. This research has been supported by the CAS Interdisciplinary Innovation Team (grant no. JCTD-201804), the National Natural Science Foundation of China (grant nos. 41877367, 91843301, and 21707157), and the Sanming Project of Medicine in Shenzhen (grant no. SZSM201811070).

Review statement. This paper was edited by Leiming Zhang and reviewed by two anonymous referees.

\section{References}

Barkay, T., Kroer, N., and Poulain, A. J.: Some like it cold: microbial transformations of mercury in polar regions, Polar Res., 30, 15469, https://doi.org/10.3402/polar.v30i0.15469, 2011.

Baya, P. A., Gosselin, M., Lehnherr, I., St. Louis, V. L., and Hintelmann, H.: Determination of Monomethylmercury and Dimethylmercury in the Arctic Marine Boundary Layer, Environ. Sci. Technol., 49, 223-232, https://doi.org/10.1021/es502601z, 2015.

Bergquist, B. A. and Blum, J. D.: Mass-dependent and -independent fractionation of $\mathrm{hg}$ isotopes by photoreduction in aquatic systems, Science, 318, 417-420, https://doi.org/10.1126/science.1148050, 2007.

Blum, J. D. and Bergquist, B. A.: Reporting of variations in the natural isotopic composition of mercury, Anal. Bioanal. Chem., 388, 353-359, https://doi.org/10.1007/s00216-007-1236-9, 2007.

Blum, J. D., Sherman, L. S., and Johnson, M. W.: Mercury Isotopes in Earth and Environmental Sciences, Annu. Rev. Earth Planet. Sc., 42, 249-269, https://doi.org/10.1146/annurev-earth-050212124107, 2014.

Cantrell, C. A.: Technical Note: Review of methods for linear least-squares fitting of data and application to atmospheric chemistry problems, Atmos. Chem. Phys., 8, 5477-5487, https://doi.org/10.5194/acp-8-5477-2008, 2008.

Chen, J. B., Hintelmann, H., Feng, X. B., and Dimock, B.: Unusual fractionation of both odd and even mercury isotopes in precipitation from Peterborough, ON, Canada, Geochim. Cosmochim. Ac., 90, 33-46, https://doi.org/10.1016/j.gca.2012.05.005, 2012.

Ci, Z., Zhang, X., and Wang, Z.: Elemental mercury in coastal seawater of Yellow Sea, China: Temporal variation and air-sea exchange, Atmos. Environ., 45, 183-190, https://doi.org/10.1016/j.atmosenv.2010.09.025, $2011 \mathrm{a}$.

Ci, Z., Zhang, X., Wang, Z., and Wang, C.: Mass balance of mercury for the Yellow Sea downwind and downstream of East Asia: the preliminary results, uncertainties and future research priorities, Biogeochemistry, 118, 243-255, https://doi.org/10.1007/s10533013-9925-2, 2014.

Ci, Z., Wang, C., Wang, Z., and Zhang, X.: Elemental mercury $(\mathrm{Hg}(0))$ in air and surface waters of the Yellow Sea during late spring and late fall 2012: Concentration, spatial- 
temporal distribution and air/sea flux, Chemosphere, 119, 199208, https://doi.org/10.1016/j.chemosphere.2014.05.064, 2015.

Ci, Z. J., Zhang, X. S., Wang, Z. W., and Niu, Z. C.: Atmospheric gaseous elemental mercury (GEM) over a coastal/rural site downwind of East China: Temporal variation and long-range transport, Atmos. Environ., 45, 2480-2487, https://doi.org/10.1016/j.atmosenv.2011.02.043, 2011 b.

Das, R., Wang, X., Khezri, B., Webster, R. D., Sikdar, P. K., and Datta, S.: Mercury isotopes of atmospheric particle bound mercury for source apportionment study in urban Kolkata, India, Elementa, 4, 000098, https://doi.org/10.12952/journal.elementa.000098, 2016.

De Simone, F., Gencarelli, C., Hedgecock, I., and Pirrone, N.: Global atmospheric cycle of mercury: a model study on the impact of oxidation mechanisms, Environ. Sci. Pollut. R., 21, 41104123, https://doi.org/10.1007/s11356-013-2451-x, 2013.

Demers, J. D., Blum, J. D., and Zak, D. R.: Mercury isotopes in a forested ecosystem: Implications for air-surface exchange dynamics and the global mercury cycle, Global Biogeochem. Cy., 27, 222-238, https://doi.org/10.1002/Gbc.20021, 2013.

Demers, J. D., Sherman, L. S., Blum, J. D., Marsik, F. J., and Dvonch, J. T.: Coupling atmospheric mercury isotope ratios and meteorology to identify sources of mercury impacting a coastal urban-industrial region near Pensacola, Florida, USA, Global Biogeochem. Cy., 29, 1689-1705, https://doi.org/10.1002/2015GB005146, 2015.

Enrico, M., Roux, G. L., Marusczak, N., Heimbürger, L.-E., Claustres, A., Fu, X., Sun, R., and Sonke, J. E.: Atmospheric Mercury Transfer to Peat Bogs Dominated by Gaseous Elemental Mercury Dry Deposition, Environ. Sci. Technol., 50, 2405-2412, https://doi.org/10.1021/acs.est.5b06058, 2016.

Estrade, N., Carignan, J., Sonke, J. E., and Donard, O. F.: Mercury isotope fractionation during liquid-vapor evaporation experiments, Geochim. Cosmochim. Ac., 73, 2693-2711, https://doi.org/10.1016/j.gca.2009.01.024, 2009.

Estrade, N., Carignan, J., Sonke, J. E., and Donard, O. F.: Measuring $\mathrm{Hg}$ Isotopes in Bio-Geo-Environmental Reference Materials, Geostand. Geoanal. Res., 34, 79-93, https://doi.org/10.1111/j.1751-908X.2009.00040.x, 2010.

Feng, X., Lu, J. Y., Grègoire, D. C., Hao, Y., Banic, C. M., and Schroeder, W. H.: Analysis of inorganic mercury species associated with airborne particulate matter/aerosols: method development, Anal. Bioanal. Chem., 380, 683-689, https://doi.org/10.1007/s00216-004-2803-y, 2004.

Fu, X., Marusczak, N., Wang, X., Gheusi, F., and Sonke, J. E.: Isotopic Composition of Gaseous Elemental Mercury in the Free Troposphere of the Pic du Midi Observatory, France, Environ. Sci. Technol., 50, 5641-5650, https://doi.org/10.1021/acs.est.6b00033, 2016.

Fu, X., Yang, X., Tan, Q., Ming, L., Lin, T., Lin, C.-J., $\mathrm{Li}$, X., and Feng, X.: Isotopic Composition of Gaseous Elemental Mercury in the Marine Boundary Layer of East China Sea, J. Geophys. Res.-Atmos., 123, 7656-7669, https://doi.org/10.1029/2018jd028671, 2018.

Fu, X., Zhang, H., Feng, X., Tan, Q., Ming, L., Liu, C., and Zhang, L.: Domestic and Transboundary Sources of Atmospheric Particulate Bound Mercury in Remote Areas of China: Evidence from Mercury Isotopes, Environ. Sci. Technol., 53, 1947-1957, https://doi.org/10.1021/acs.est.8b06736, 2019a.
Fu, X., Zhang, H., Liu, C., Zhang, H., Lin, C.-J., and Feng, X.: Significant Seasonal Variations in Isotopic Composition of Atmospheric Total Gaseous Mercury at Forest Sites in China Caused by Vegetation and Mercury Sources, Environ. Sci. Technol., 53, 13748-13756, https://doi.org/10.1021/acs.est.9b05016, $2019 \mathrm{~b}$.

Fu, X. W., Feng, X. B., Zhang, G., Xu, W. H., Li, X. D., Yao, H., Liang, P., Li, J., Sommar, J., Yin, R. S., and Liu, N.: Mercury in the marine boundary layer and seawater of the South China Sea: Concentrations, sea/air flux, and implication for land outflow, J. Geophys. Res.-Atmos., 115, D06303, https://doi.org/10.1029/2009jd012958, 2010.

$\mathrm{Fu}, \mathrm{X}$. W., Heimburger, L. E., and Sonke, J. E.: Collection of atmospheric gaseous mercury for stable isotope analysis using iodineand chlorine-impregnated activated carbon traps, J. Anal. Atom. Spectrom., 29, 841-852, https://doi.org/10.1039/C3ja50356a, 2014.

Fu, X. W., Zhang, H., Yu, B., Wang, X., Lin, C.-J., and Feng, X. B.: Observations of atmospheric mercury in China: a critical review, Atmos. Chem. Phys., 15, 9455-9476, https://doi.org/10.5194/acp-15-9455-2015, 2015.

Geng, H., Yin, R., and Li, X.: An optimized protocol for high precision measurement of $\mathrm{Hg}$ isotopic compositions in samples with low concentrations of $\mathrm{Hg}$ using MC-ICP-MS, J. Anal. Atom. Spectrom., 33, 1932-1940, https://doi.org/10.1039/C8JA00255J, 2018.

Gratz, L. E., Keeler, G. J., Blum, J. D., and Sherman, L. S.: Isotopic composition and fractionation of mercury in Great Lakes precipitation and ambient air, Environ. Sci. Technol., 44, 7764-7770, https://doi.org/10.1021/es100383w, 2010.

Hedgecock, I. M. and Pirrone, N.: Mercury and photochemistry in the marine boundary layer-modelling studies suggest the in situ production of reactive gas phase mercury, Atmos. Environ., 35, 3055-3062, https://doi.org/10.1016/S1352-2310(01)001091,2001

Hedgecock, I. M. and Pirrone, N.: Chasing quicksilver: Modeling the atmospheric lifetime of $\mathrm{Hg} 0(\mathrm{~g})$ in the marine boundary layer at various latitudes, Environ. Sci. Technol., 38, 69-76, https://doi.org/10.1021/es034623z, 2004.

Holmes, C. D., Jacob, D. J., Mason, R. P., and Jaffe, D. A.: Sources and deposition of reactive gaseous mercury in the marine atmosphere, Atmos. Environ., 43, 2278-2285, https://doi.org/10.1016/j.atmosenv.2009.01.051, 2009.

Holmes, C. D., Jacob, D. J., Corbitt, E. S., Mao, J., Yang, X., Talbot, R., and Slemr, F.: Global atmospheric model for mercury including oxidation by bromine atoms, Atmos. Chem. Phys., 10, 12037-12057, https://doi.org/10.5194/acp-10-120372010, 2010.

Horowitz, H. M., Jacob, D. J., Zhang, Y., Dibble, T. S., Slemr, F., Amos, H. M., Schmidt, J. A., Corbitt, E. S., Marais, E. A., and Sunderland, E. M.: A new mechanism for atmospheric mercury redox chemistry: implications for the global mercury budget, Atmos. Chem. Phys., 17, 6353-6371, https://doi.org/10.5194/acp17-6353-2017, 2017.

Huang, Q., Liu, Y., Chen, J., Feng, X., Huang, W., Yuan, S., Cai, H., and Fu, X.: An improved dual-stage protocol to preconcentrate mercury from airborne particles for precise isotopic measurement, J. Anal. Atom. Spectrom., 30, 957-966, https://doi.org/10.1039/c4ja00438h, 2015. 
Huang, Q., Chen, J., Huang, W., Fu, P., Guinot, B., Feng, X., Shang, L., Wang, Z., Wang, Z., Yuan, S., Cai, H., Wei, L., and Yu, B.: Isotopic composition for source identification of mercury in atmospheric fine particles, Atmos. Chem. Phys., 16, 11773-11786, https://doi.org/10.5194/acp-16-11773-2016, 2016.

Koster van Groos, P. G., Esser, B. K., Williams, R. W., and Hunt, J. R.: Isotope effect of mercury diffusion in air, Environ. Sci. Technol., 48, 227-233, https://doi.org/10.1021/es4033666, 2014.

Laurier, F. J., Mason, R. P., Whalin, L., and Kato, S.: Reactive gaseous mercury formation in the North Pacific Ocean's marine boundary layer: A potential role of halogen chemistry, J. Geophys. Res.-Atmos., 108, 4529, https://doi.org/10.1029/2003JD003625, 2003.

Lin, C. J. and Pehkonen, S. O.: The chemistry of atmospheric mercury: a review, Atmos. Environ., 33, 2067-2079, https://doi.org/10.1016/S1352-2310(98)00387-2, 1999.

Obrist, D., Tas, E., Peleg, M., Matveev, V., Faïn, X., Asaf, D., and Luria, M.: Bromine-induced oxidation of mercury in the mid-latitude atmosphere, Nat. Geosci., 4, 22-26, https://doi.org/10.1038/ngeo1018, 2011.

Peleg, M., Tas, E., Obrist, D., Matveev, V., Moore, C., Gabay, M., and Luria, M.: Observational Evidence for Involvement of Nitrate Radicals in Nighttime Oxidation of Mercury, Environ. Sci. Technol., 49, 14008-14018, https://doi.org/10.1021/acs.est.5b03894, 2015.

Rolison, J. M., Landing, W. M., Luke, W., Cohen, M., and Salters, V. J. M.: Isotopic composition of species-specific atmospheric $\mathrm{Hg}$ in a coastal environment, Chem. Geol., 336, 37-49, https://doi.org/10.1016/j.chemgeo.2012.10.007, 2013.

Rolph, G., Stein, A., and Stunder, B.: Real-time Environmental Applications and Display sYstem: READY, Environ. Modell. Softw., 95, 210-228, https://doi.org/10.1016/j.envsoft.2017.06.025, 2017.

Schauble, E. A.: Role of nuclear volume in driving equilibrium stable isotope fractionation of mercury, thallium, and other very heavy elements, Geochim. Cosmochim. Ac., 71, 2170-2189, https://doi.org/10.1016/j.gca.2007.02.004, 2007.

Schroeder, W. H. and Munthe, J.: Atmospheric mercury - an overview, Atmos. Environ., 32, 809-822, https://doi.org/10.1016/S1352-2310(97)00293-8, 1998.

Sprovieri, F., Hedgecock, I. M., and Pirrone, N.: An investigation of the origins of reactive gaseous mercury in the Mediterranean marine boundary layer, Atmos. Chem. Phys., 10, 3985-3997, https://doi.org/10.5194/acp-10-3985-2010, 2010.

Stein, A. F., Draxler, R. R., Rolph, G. D., Stunder, B. J. B., Cohen, M. D., and Ngan, F.: NOAA's HYSPLIT Atmospheric Transport and Dispersion Modeling System, B. Am. Meteorol. Soc., 96, 2059-2077, https://doi.org/10.1175/BAMS-D-14$00110.1,2015$.

Sun, G., Sommar, J., Feng, X., Lin, C.-J., Ge, M., Wang, W., Yin, R., $\mathrm{Fu}, \mathrm{X}$., and Shang, L.: Mass-Dependent and -Independent Fractionation of Mercury Isotope during Gas-Phase Oxidation of Elemental Mercury Vapor by Atomic $\mathrm{Cl}$ and $\mathrm{Br}$, Environ. Sci. Technol., 50, 9232-9241, https://doi.org/10.1021/acs.est.6b01668, 2016.

Sun, R., Enrico, M., Heimbürger, L.-E., Scott, C., and Sonke, J. E.: A double-stage tube furnace-acid-trapping protocol for the pre-concentration of mercury from solid samples for isotopic analysis, Anal. Bioanal. Chem., 405, 6771-6781, https://doi.org/10.1007/s00216-013-7152-2, 2013.

Sun, R., Sonke, J. E., Heimbürger, L.-E., Belkin, H. E., Liu, G., Shome, D., Cukrowska, E., Liousse, C., Pokrovsky, O. S., and Streets, D. G.: Mercury Stable Isotope Signatures of World Coal Deposits and Historical Coal Combustion Emissions, Environ. Sci. Technol., 48, 7660-7668, https://doi.org/10.1021/es501208a, 2014.

Timonen, H., Ambrose, J. L., and Jaffe, D. A.: Oxidation of elemental $\mathrm{Hg}$ in anthropogenic and marine airmasses, Atmos. Chem. Phys., 13, 2827-2836, https://doi.org/10.5194/acp-132827-2013, 2013.

UN Environment: Global Mercury Assessment 2018, UN Environment Programme, Chemicals and Health Branch Geneva, Switzerland, available at: https://www.unenvironment. org/resources/publication/global-mercury-assessment-2018, last access: 10 April 2019.

Wang, C., Ci, Z., Wang, Z., Zhang, X., and Guo, J.: Speciated atmospheric mercury in the marine boundary layer of the Bohai Sea and Yellow Sea, Atmos. Environ., 131, 360-370, https://doi.org/10.1016/j.atmosenv.2016.02.021, 2016a.

Wang, C., Wang, Z., Ci, Z., Zhang, X., and Tang, X.: Spatial-temporal distributions of gaseous element mercury and particulate mercury in the Asian marine boundary layer, Atmos. Environ., 126, 107-116, https://doi.org/10.1016/j.atmosenv.2015.11.036, 2016b.

Wang, Z., Chen, J., Feng, X., Hintelmann, H., Yuan, S., Cai, H., Huang, Q., Wang, S., and Wang, F.: Mass-dependent and mass-independent fractionation of mercury isotopes in precipitation from Guiyang, SW China, C. R. Geosci., 347, 358-367, https://doi.org/10.1016/j.crte.2015.02.006, 2015.

Weiss-Penzias, P., Jaffe, D. A., McClintick, A., Prestbo, E. M., and Landis, M. S.: Gaseous Elemental Mercury in the Marine Boundary Layer:? Evidence for Rapid Removal in Anthropogenic Pollution, Environ. Sci. Technol., 37, 3755-3763, https://doi.org/10.1021/es0341081, 2003.

Xu, H., Sonke, J. E., Guinot, B., Fu, X., Sun, R., Lanzanova, A., Candaudap, F., Shen, Z., and Cao, J.: Seasonal and Annual Variations in Atmospheric $\mathrm{Hg}$ and $\mathrm{Pb}$ Isotopes in Xi'an, China, Environ. Sci. Technol., 51, 3759-3766, https://doi.org/10.1021/acs.est.6b06145, 2017.

Ye, Z., Mao, H., Lin, C.-J., and Kim, S. Y.: Investigation of processes controlling summertime gaseous elemental mercury oxidation at midlatitudinal marine, coastal, and inland sites, Atmos. Chem. Phys., 16, 8461-8478, https://doi.org/10.5194/acp16-8461-2016, 2016.

Yin, R., Feng, X., Foucher, D., Shi, W., Zhao, Z., and Wang, J.: High precision determination of mercury isotope ratios using online mercury vapor generation system coupled with multicollector inductively coupled plasma-mass spectrometer, Chinese J. Anal. Chem., 38, 929-934, https://doi.org/10.1016/S18722040(09)60055-4, 2010.

Yin, R., Feng, X., and Meng, B.: Stable mercury isotope variation in rice plants (Oryza sativa L.) from the Wanshan mercury mining district, SW China, Environ. Sci. Technol., 47, 2238-2245, https://doi.org/10.1021/es304302a, 2013.

Yu, B., Fu, X., Yin, R., Zhang, H., Wang, X., Lin, C.-J., Wu, C., Zhang, Y., He, N., Fu, P., Wang, Z., Shang, L., Sommar, J., Sonke, J. E., Maurice, L., Guinot, B., and Feng, 
X.: Isotopic Composition of Atmospheric Mercury in China: New Evidence for Sources and Transformation Processes in Air and in Vegetation, Environ. Sci. Technol., 50, 9262-9269, https://doi.org/10.1021/acs.est.6b01782, 2016.

Yu, B., Yang, L., Wang, L., Liu, H., Xiao, C., Liang, Y., Liu, Q., Yin, Y., Hu, L., Shi, J., and Jiang, G.: New evidence for atmospheric mercury transformations in the marine boundary layer, Zenodo, https://doi.org/10.5281/zenodo.3748831, 2020a.

Yu, B., Yang, L., Wang, L., Liu, H., Xiao, C., Liang, Y., Liu, Q., Yin, Y., Hu, L., Shi, J., and Jiang, G.: New evidence for atmospheric mercury transformations in the marine boundary layer-Part II, Zenodo, https://doi.org/10.5281/zenodo.3871222, 2020b.

Yuan, S., Chen, J., Cai, H., Yuan, W., Wang, Z., Huang, Q., Liu, Y., and Wu, X.: Sequential samples reveal significant variation of mercury isotope ratios during single rainfall events, Sci. Total Environ., 624, 133-144, https://doi.org/10.1016/j.scitotenv.2017.12.082, 2018.
Zheng, W., Foucher, D., and Hintelmann, H.: Mercury isotope fractionation during volatilization of $\mathrm{Hg}(0)$ from solution into the gas phase, J. Anal. Atom. Spectrom., 22, 1097-1104, https://doi.org/10.1039/B705677j, 2007.

Zheng, W. and Hintelmann, H.: Mercury isotope fractionation during photoreduction in natural water is controlled by its Hg/DOC ratio, Geochim. Cosmochim. Ac., 73, 6704-6715, https://doi.org/10.1016/j.gca.2009.08.016, 2009.

Zheng, W. and Hintelmann, H.: Isotope fractionation of mercury during its photochemical reduction by low-molecularweight organic compounds, J. Phys. Chem. A, 114, 4246-4253, https://doi.org/10.1021/jp9111348, 2010. 